\title{
Valeur alimentaire de régimes à base de cactus inerme (Opuntia ficus indica var. Inermis) et d'Atriplex (Atriplex nummularia)
}

\author{
A Nefzaoui \\ Laboratoire de Nutrition Animale, INRA de Tunisie, rue Hédi Karray, 2049 Ariana, Tunisie.
}

Cette recherche se situe dans le cadre de I'utilisation des arbustes fourragers en alimentation animale. L'objectif spécifique à cet essai est la détermination de la valeur alimentaire de régimes à base de cactus inerme (Opuntia ficus indica, var. Inermis) et d'Atriplex nummularia.

Quinze antenais de race Barbarine dont le poids vif initial varie de 27 à $35 \mathrm{~kg}$ ont été répartis de façon aléatoire en trois lots de cinq têtes chacun. Chaque lot a reçu un régime composé d'atriplex et de cactus en quantités variables, et une quantité constante de paille (200 g par jour) et de complément minéral et vitaminique (30 g par jour). Les animaux ont été logés individuellement dans des cages à métabolisme, et la digestibilité a été mesurée par la méthode de collecte totale des fèces.
Les résultats montrent que l'alimentation des ovins avec des régimes à base de cactus et d'atriplex ( $80 \%$ de la MS de la ration) est techniquement "faisable". Le cactus est une bonne source énergétique et l'atriplex une bonne source de matières azotées. Leur association ne peut qu'être bénéfique pour les animaux. Les régimes testés permettent de couvrir largement les besoins d'entretien aussi bien en énergie qu'en azote. Les niveaux alimentaires sont voisins de 1,7.

Le cactus inerme peut représenter $55 \%$ de la MS de la ration ingérée, soit 6 à $7 \mathrm{~kg}$ de produit brut, sans provoquer des troubles digestifs. La seule précaution à envisager est de distribuer d'abord une petite quantité d'un aliment «fibreux" tel que de la paille ou du foin.
Régimes

Composition des régimes ( $\%$ MS totale)

Atriplex

Cactus

Paille

Digestibilité des régimes (\%)

Matière organique

Matières azotées

Quantités ingérées (g MS/j/tête)

Matière organique digestible

Matière azotée digestible
R1

59

21

17

67,7

74,5

941

$38,1(165)$

$6,9(230)$
$\mathrm{R} 2$

42

38

17

69,3

76,6

930

$38,9(170)$

$5,9(187)$
R3

24

56

17

74,4

75,5

983

41,9(182)

4,8(165)

Les valeurs entre ( ) correspondent aux apports exprimés en \% des besoins d'entretien (INRA, 1978). 